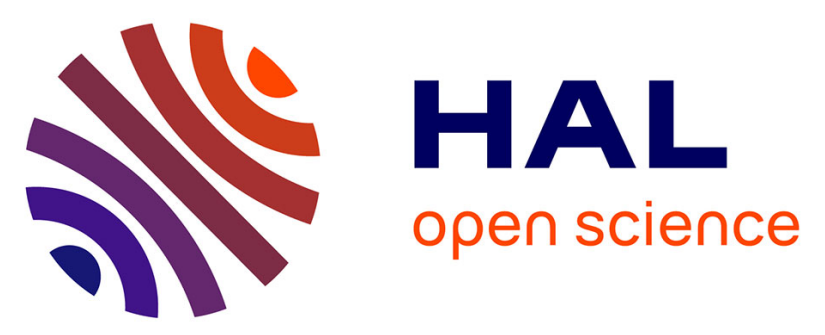

\title{
Association Between Initial Treatment Strategy and Long-term Survival in Pulmonary Arterial Hypertension
}

Athénaïs Boucly, Laurent Savale, Xavier Jaïs, Fabrice Bauer, Emmanuel

Bergot, Laurent Bertoletti, Antoine Beurnier, Arnaud Bourdin, Hélène

Bouvaist, Sophie Bulifon, et al.

\section{To cite this version:}

Athénaïs Boucly, Laurent Savale, Xavier Jaïs, Fabrice Bauer, Emmanuel Bergot, et al.. Association Between Initial Treatment Strategy and Long-term Survival in Pulmonary Arterial Hypertension. American Journal of Respiratory and Critical Care Medicine, 2021, 204 (7), pp.842-854. 10.1164/rccm.202009-3698OC . hal-03274671

\section{HAL Id: hal-03274671 \\ https://hal.science/hal-03274671}

Submitted on 6 Oct 2021

HAL is a multi-disciplinary open access archive for the deposit and dissemination of scientific research documents, whether they are published or not. The documents may come from teaching and research institutions in France or abroad, or from public or private research centers.
L'archive ouverte pluridisciplinaire $\mathbf{H A L}$, est destinée au dépôt et à la diffusion de documents scientifiques de niveau recherche, publiés ou non, émanant des établissements d'enseignement et de recherche français ou étrangers, des laboratoires publics ou privés. 


\title{
Association between Initial Treatment Strategy and Long-Term Survival in Pulmonary Arterial Hypertension
}

\author{
Athénaïs Boucly ${ }^{1,2,3}$, Laurent Savale ${ }^{1,2,3}$, Xavier Jaïs ${ }^{1,2,3}$, Fabrice Bauer ${ }^{4}$, Emmanuel Bergot ${ }^{5}$, Laurent Bertoletti ${ }^{6}$, \\ Antoine Beurnier ${ }^{1,2,3}$, Arnaud Bourdin ${ }^{7,8}$, Hélène Bouvaist ${ }^{9}$, Sophie Bulifon ${ }^{1,2,3}$, Céline Chabanne ${ }^{10}$, Ari Chaouat ${ }^{11}$, \\ Vincent Cottin ${ }^{12}$, Claire Dauphin ${ }^{13}$, Bruno Degano ${ }^{14}$, Pascal De Groote ${ }^{15}$, Nicolas Favrolt ${ }^{16}$, Yuanchao Feng ${ }^{17}$, \\ Delphine Horeau-Langlard ${ }^{18}$, Mitja Jevnikar ${ }^{1,2,3}$, Etienne-Marie Jutant ${ }^{1,2,3}$, Zhiying Liang ${ }^{17}$, Pascal Magro ${ }^{19}$, \\ Pierre Mauran $^{20}$, Pamela Moceri ${ }^{21}$, Jean-François Mornex ${ }^{12}$, Sylvain Palat ${ }^{22}$, Florence Parent ${ }^{1,2,3}$, \\ François Picard ${ }^{23,24}$, Jérémie Pichon ${ }^{1,2,3}$, Patrice Poubeau ${ }^{25}$, Grégoire Prévot ${ }^{26}$, Sébastien Renard ${ }^{27}$ \\ Martine Reynaud-Gaubert ${ }^{28}$, Marianne Riou ${ }^{29}$, Pascal Roblot ${ }^{30}$, Olivier Sanchez ${ }^{31}$, Andrei Seferian ${ }^{1,2,3}$, \\ Cécile Tromeur $^{32}$, Jason Weatherald ${ }^{17,33}$, Gérald Simonneau ${ }^{1,2,3}$, David Montani ${ }^{1,2,3}$, Marc Humbert ${ }^{1,2,3}$, and \\ Olivier Sitbon ${ }^{1,2,3}$
}

\begin{abstract}
Rationale: The relationship between the initial treatment strategy and survival in pulmonary arterial hypertension (PAH) remains uncertain.
\end{abstract}

Objectives: To evaluate the long-term survival of patients with PAH categorized according to the initial treatment strategy.

Methods: A retrospective analysis of incident patients with idiopathic, heritable, or anorexigen-induced PAH enrolled in the French Pulmonary Hypertension Registry (January 2006 to December 2018) was conducted. Survival was assessed according to the initial strategy: monotherapy, dual therapy, or triple-combination therapy (two oral medications and a parenteral prostacyclin).

Measurements and Main Results: Among 1,611 enrolled patients, 984 were initiated on monotherapy, 551 were initiated on dual therapy, and 76 were initiated on triple therapy. The triplecombination group was younger and had fewer comorbidities but had a higher mortality risk. The survival rate was higher with the use of triple therapy ( $91 \%$ at $5 \mathrm{yr}$ ) as compared with dual therapy or monotherapy (both $61 \%$ at $5 \mathrm{yr})(P<0.001)$. Propensity score matching of age, sex, and pulmonary vascular resistance also showed significant differences between triple therapy and dual therapy (10-yr survival, $85 \%$ vs. $65 \%)$. In high-risk patients $(n=243)$, the survival rate was higher with triple therapy than with monotherapy or dual therapy, whereas there was no difference between monotherapy and double therapy. In intermediate-risk patients $(n=1,134)$, survival improved with an increasing number of therapies. In multivariable Cox regression, triple therapy was independently associated with a lower risk of death (hazard ratio, 0.29; 95\% confidence interval, 0.11-0.80; $P=0.017)$. Among the 148 patients initiated on a parenteral prostacyclin, those on triple therapy had a higher survival rate than those on monotherapy or dual therapy.

Conclusions: Initial triple-combination therapy that includes parenteral prostacyclin seems to be associated with a higher survival rate in $\mathrm{PAH}$, particularly in the youngest high-risk patients.

Keywords: pulmonary hypertension; pulmonary arterial hypertension; survival; therapeutics

(Received in original form September 29, 2020; accepted in final form June 28, 2021)

Author Contributions: A. Boucly contributed to the literature search, study design, data collection, statistical analysis, figures, interpretation of data, and writing. L.S., X.J., F.B., E.B., L.B., A. Beurnier, A. Bourdin, H.B., S.B., C.C., A.C., V.C., C.D., B.D., P.D.G., N.F., D.H.-L., M.J., E.-M.J ., P. Magro, P. Mauran, P. Moceri, J.-F.M., S.P., F. Parent, F. Picard, J.P., P.P., G.P., S.R., M.R.-G., M.R., P.R., O. Sanchez, A.S., C.T., J.W., G.S. and D.M. contributed to data collection and interpretation, revision of the manuscript for important intellectual content, and final approval. Y.F. and Z.L. contributed to the statistical analysis. M.H. and O. Sitbon contributed to the study design, analysis, interpretation of data, revision of the manuscript for important intellectual content, and final approval.

Correspondence and requests for reprints should be addressed to Olivier Sitbon, M.D., Ph.D., Service de Pneumologie et Soins Intensifs, Hôpital Bicêtre, 78 Rue du Général Leclerc, 94275 Le Kremlin-Bicêtre, France. E-mail: olivier.sitbon@universite-paris-saclay.fr. 
${ }^{1}$ Faculté de Médecine, Université Paris-Saclay, Le Kremlin-Bicêtre, France; ${ }^{2}$ Service de Pneumologie et Soins Intensifs, Hôpital Bicêtre, Assistance Publique-Hôpitaux de Paris, Le Kremlin-Bicêtre, France; ' Unité Mixte de Recherche S999, Hôpital Marie Lannelongue-Institut National de la Santé et de la Recherche Médicale, Le Plessis-Robinson, France; ${ }^{4}$ Unité 1096, Département de Chirurgie Cardiaque, Centre Hospitalier Universitaire de Rouen, Université de Rouen-Institut National de la Santé et de la Recherche Médicale, Rouen, France; 5 Unité de Formation et de Recherche en Santé, Service de Pneumologie et Oncologie Thoracique, Centre

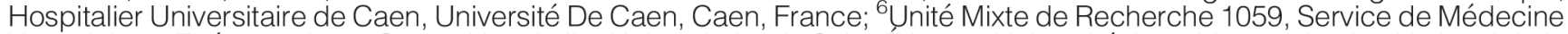
Vasculaire et Thérapeutique, Centre Hospitalier Universitaire de Saint-Étienne, Université Jean-Monnet-Institut National de la Santé et de la Recherche Médicale, Saint-Étienne, France; ' 7 Service de Pneumologie, Centre Hospitalier Universitaire de Montpellier, Université de Montpellier, Montpellier, France; ' ${ }^{2}$ Laboratoire de Physiologie et Médecine Expérimentale, Centre Hospitalier Universitaire de Montpellier, Université de Montpellier-Centre National de la Recherche Scientifique-Institut National de la Santé et de la Recherche Médicale, Montpellier, France; ${ }^{9}$ Service de Cardiologie and ${ }^{14}$ Service de Pneumologie, Hôpital Universitaire Grenoble-Alpes, Grenoble, France; ${ }^{10}$ Unité Mixte de Recherche 1099: Laboratoire Traitement du Signal et de l'Image, Service de Cardiologie et Maladies Vasculaires, Centre Hospitalier Universitaire de Rennes, Université de Rennes-Institut National de la Santé et de la Recherche Médicale, Rennes, France; ${ }^{11}$ Unité Mixte de Recherche S1116, Département de Pneumologie, Faculté de Médecine de Nancy, Centre Hospitalier Régional Universitaire de Nancy, Université de Lorraine-Institut National de la Santé et de la Recherche Médicale, Vandouuvre-lès-Nancy, France; ${ }^{12}$ Unité Mixte de Recherche 754: Infections Virales et Pathologie Comparée, Hospices Civils de Lyon, Université Lyon 1-Institut National de la Recherche Agronomique Centre National de Référence des Maladies Pulmonaires Rares, Lyon, France; ${ }^{13}$ Service de Cardiologie et Maladies Vasculaires, Hôpital Gabriel Montpied, Centre Hospitalier Universitaire de Clermont-Ferrand, Clermont-Ferrand, France; ${ }^{15}$ Unité 1167, Service de Cardiologie, Centre Hospitalier Universitaire de Lille, Université de Lille-Institut Pasteur de Lille-Institut National de la Santé et de la Recherche Médicale, Lille, France; ${ }^{16}$ Service de Pneumologie et Soins Intensifs Respiratoires, Centre Hospitalier Universitaire de François Mitterrand, Dijon, France; ${ }^{17}$ Libin Cardiovascular Institute, University of Calgary, Calgary, Alberta, Canada; ${ }^{18}$ Service de Pneumologie, Hôpital Laënnec, Centre Hospitalier Universitaire de Nantes, Nantes, France; ${ }^{9}$ Service de Pneumologie, Centre Hospitalier Universitaire de Tours, Tours, France; ${ }^{20}$ Unité de Cardiologie Pédiatrique et Congénitale, CHU de Reims, American Memorial Hospital, Reims, France; ${ }^{21}$ Unité de Recherche Clinique Côte d'Azur, Service de Cardiologie, Centre Hospitalier Universitaire de Nice, Université Côte d'Azur, Nice, France; ${ }^{22}$ Département de Médecine Interne, Centre Hospitalier Universitaire de Dupuytren, Limoges, France; ${ }^{23}$ Unité de Traitement de l'Insuffisance Cardiaque and ${ }^{24}$ Centre de Compétences de l'Hypertension Pulmonaire, Hốpital Cardiologique Haut-Lévêque, Centre Hospitalier Universitaire de Bordeaux, Université de Bordeaux, Bordeaux, France; ${ }^{25}$ Service de Médecine Interne, Centre Hospitalier Universitaire de la Réunion, Saint-Pierre de la Réunion, France; ${ }^{26}$ Service de Pneumologie, Hôpital Larrey, Centre Hospitalier Universitaire de Toulouse, Toulouse, France; ${ }^{27}$ Service de Cardiologie, Cẹntre Régional de Compétences de l'Hypertension Pulmonaire, Hôpital La Timone, Marseille, France; ${ }^{28}$ Service de Pneumologie, Equipe de Transplantation Pulmonaire, Centre de Compétences des Maladies Pulmonaires Rares, Aix-Marseille Université-Hôpital Nord, Assistance Publique-Hôpitaux de Marseille, Marseille, France; ${ }^{29}$ Département de Pneumologie, Nouvel Hôpital Civil, Strasbourg, France; ${ }^{3}$ Service de Médecine Interne, Maladies Infectieuses et Tropicales, Hôpital Universitaire de Poitiers, Poitiers, France; ${ }^{31}$ Service de Pneumologie, Université de Paris-Hôpital Européen Georges-Pompidou, Assistance Publique-Hôpitaux de Paris, Paris, France; ${ }^{2}$ Unité 1412: Centre d'Investigation Clinique de Brest, Département de Médeçine Interne et Pneumologie, Centre Hospitalier Universitaire de Brest-Université de Bretagne Occidentale-Institut National de la Santé et de la Recherche Médicale, Brest, France; and ${ }^{33}$ Division of Respirology, Department of Medicine, University of Calgary, Calgary, Alberta, Canada

After confirmation of a pulmonary arterial hypertension (PAH) diagnosis, the 2015 joint European Society of Cardiology and European Respiratory Society (ESC/ERS) guidelines for the diagnosis and treatment of pulmonary hypertension $(\mathrm{PH})$ and the recent World Symposium on $\mathrm{PH}$ proceedings recommend tailoring an initial treatment strategy according to the degree of risk for adverse outcomes (1-3).

For the most severe cases with a high risk of death (estimated to be $>10 \%$ at $1 \mathrm{yr}$ ), initial combination therapy with intravenous prostacyclin is recommended (1-3). The level of evidence for this recommendation is, however, weak. The Bosentan Randomized trial of Endothelin Antagonist Therapy for PAH (BREATHE2) randomized controlled trial (RCT) failed to demonstrate a significant difference in the change in total pulmonary resistance between patients initiated on a dual combination of intravenous epoprostenol and bosentan and those initiated on monotherapy with epoprostenol (4). There was, however, a numerical trend in favor of combination therapy, and the practice of initially combining epoprostenol and bosentan continued in several centers. A retrospective analysis of 23 patients with PAH initiated on therapy by using this strategy at the French PH Referral Center showed long-term improvement in terms of the New York Heart Association (NYHA) functional class (FC), exercise capacity, and hemodynamics (5). Subsequently, the effect of an initial triplecombination therapy that included parenteral prostacyclin, an endothelinreceptor antagonist, and a PDE5 (phosphodiesterase type 5) inhibitor was assessed in two observational studies $(6,7)$. Marked improvements in terms of the NYHA FC, exercise capacity, and hemodynamics were reported in incident patients with severe idiopathic or heritable PAH after 4 months of initial treatment with intravenous epoprostenol, bosentan, and sildenafil (6). Similar results were recently reported in patients with $\mathrm{PAH}$ treated with an initial combination of subcutaneous treprostinil, ambrisentan, and tadalafil (7).

For patients at low or intermediate risk at diagnosis, either monotherapy or dual oral combination therapy is recommended (1-3). The Ambrisentan and Tadalafil in 


\section{Scientific Knowledge on the Subject: European pulmonary} hypertension guidelines and the latest World Symposium on Pulmonary Hypertension proceedings recommend tailoring an initial treatment strategy according to a patient's risk for adverse outcomes. The relationships among the initial treatment strategy, risk assessment at diagnosis, and longterm outcomes are unclear.

\section{What This Study Adds to the}

Field: This study evaluated the association between long-term survival and the initial treatment strategy in a large cohort of patients with newly diagnosed idiopathic, heritable, or anorexigen-induced pulmonary arterial hypertension (PAH). Initial triplecombination therapy that included parenteral prostacyclin was associated with a higher long-term survival rate for the most patients with a high risk of death at diagnosis, whereas dualcombination therapy was associated with a higher survival rate than monotherapy in patients who were at intermediate risk at diagnosis. These findings provide new evidence to support the PAH treatment algorithm presented in the European guidelines and at the Sixth World Symposium on Pulmonary Hypertension and support the utility of multidimensional risk stratification to choose the most appropriate initial treatment strategy for patients with PAH.

Patients with Pulmonary Arterial Hypertension (AMBITION) RCT demonstrated the superiority of the initial combination of two oral drugs (ambrisentan and tadalafil) over monotherapy (ambrisentan or tadalafil), with a 50\% reduction in the primary endpoint of the time to a clinical failure event being shown (8). Of note, there was no difference in the death rates between those receiving initial oral combination therapy and those receiving initial oral monotherapy $(8,9)$.

No study has assessed the impact of the initial treatment strategy on the long-term survival of patients with PAH. The aim of our retrospective study was to evaluate the long-term overall and transplant-free survival in a large incident cohort of patients with idiopathic, heritable, or anorexigen-induced $\mathrm{PAH}$ who were categorized according to the initial treatment strategy: monotherapy, dual-combination therapy, or triple-combination therapy.

Some of the results of this study were previously reported in the form of abstracts at the ERS Congress (10) and the American Thoracic Society Annual Conference (11).

\section{Methods}

This study complied with the Declaration of Helsinki. Although French law does not require ethics committee approval or informed consent for retrospective data collection, the data were anonymized and compiled according to the requirements of the French organization dedicated to privacy, information technology, and civil rights in France (Commission Nationale de l'Informatique et des Libertés). The committee approved the methods used to collect and analyze data on May 24, 2003 (approval number 842063).

\section{Patient Population}

Data were collected from the web-based French PH Registry (https://registre-htap. aphp.fr; PAHTool, Inovultus Ltd.). We reviewed data from all adult patients with newly diagnosed idiopathic, heritable, or anorexigen-induced $\mathrm{PAH}$ who were enrolled in the prospective French PH Registry between January 2006 and December 2018. We focused on this patient population to avoid any impact of an underlying associated disease (e.g., systemic sclerosis or portal hypertension) on survival. Inclusion required a baseline right heart catheterization confirming the diagnosis of $\mathrm{PAH}$, defined as a mean pulmonary arterial pressure $\geqslant 25$ $\mathrm{mm} \mathrm{Hg}$ with a mean pulmonary arterial wedge pressure $\leqslant 15 \mathrm{~mm} \mathrm{Hg}$ and pulmonary vascular resistance $(\mathrm{PVR})>3$ Wood units (WU) $(1,2)$. Only patients receiving PAH therapy within the first 3 months of $\mathrm{PAH}$ diagnosis were included. Patients were excluded if they displayed an acute vasodilator response and subsequently received only calcium-channel blockers. Patients were categorized according to their initial treatment regimen: monotherapy, dual-combination therapy, or triple- combination therapy that included intravenous or subcutaneous prostacyclin.

\section{Measurements}

Overall survival was analyzed in the overall population and according to the initial treatment regimen. The impact of the initial treatment strategy on survival was also analyzed according to the risk status at baseline, which was assessed by using the abbreviated ESC/ERS PH Guidelines risk stratification table, as previously described in SPAHR (Swedish PH Register) and COMPERA (Comparative, Prospective Registry of Newly Initiated Therapies for $\mathrm{PH})(1,2,12,13)$. The numbers of low-risk criteria present at baseline and at the first follow-up were analyzed according to the initial treatment strategy. Four low-risk criteria from the 2015 ESC/ERS PH Guidelines were evaluated: 1) NYHA FC of I-II, 2) 6-minute-walk distance (6MWD) $>440 \mathrm{~m}, 3)$ right atrial pressure $<8 \mathrm{~mm} \mathrm{Hg}$, and 4) cardiac index $\geqslant 2.5 \mathrm{~L} \cdot \mathrm{min}^{-1} \cdot \mathrm{m}^{-2}$ $(1,2,14)$. Finally, the impact of initial therapy on survival was analyzed in the subset of patients initiated on parenteral prostacyclin.

\section{Statistical Analysis}

Statistical analysis was performed by using SPSS Statistics version 26 (IBM). Continuous variables were expressed as the mean $\pm \mathrm{SD}$ or median (interquartile range [IQR], $25-75 \%)$ on the basis of the data distribution.

Survival analyses were performed by using an intent-to-treat approach. The date of diagnostic right heart catheterization was used as the starting point to determine the length of survival. The cutoff date was December 31, 2019. Overall and transplant-free survival according to the initial treatment strategy were represented by using the Kaplan-Meier method and compared by using the log rank test. In the overall survival analysis, patients who underwent a lung transplantation were censored at the date of transplantation. To correct for confounding factors, three additional survival analyses that used propensity score matching of age, sex, and PVR were performed. Two analyses compared matched samples of initial triple-combination therapy and initial dual-combination therapy (overall and transplant-free survival). The other analysis compared matched samples of initial dual-combination therapy and initial monotherapy (overall survival). 


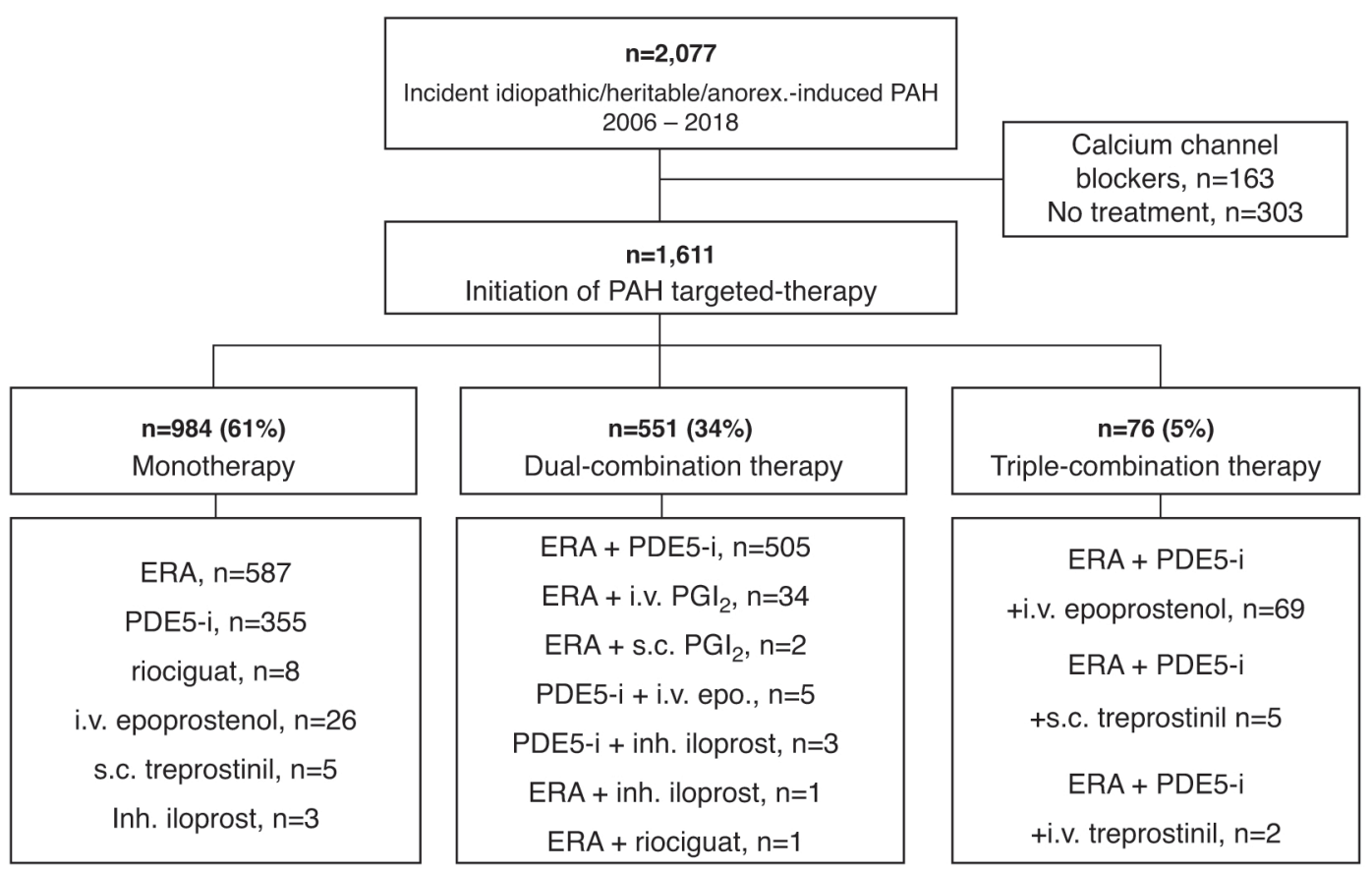

Figure 1. Study population. anorex. = anorexigen; ERA = endothelin-receptor antagonist; Inh. = inhaled; $\mathrm{PAH}=$ pulmonary arterial hypertension; PDE5-i = phosphodiesterase type 5 inhibitor.

Univariable and multivariable Cox proportional hazard regression models were performed to determine the risk of death according to baseline variables. A multivariable model was performed by using the "entry" method without a stepwise selection of variables. Candidate variables were chosen because they were known risk factors (sex, age, etiology, FC, 6MWD, hemodynamic variables, BNP [brain natriuretic peptide] or NT-proBNP [N-terminal pro-BNP]), and they had no collinearity. In addition, we included the initial treatment strategy and the year of diagnosis in the model. All comparisons were two-sided, and $P<0.05$ was considered to indicate statistical significance.

Additional analyses that include a comparison of overall and expected survival, as well as survival analysis according to the degree of risk assessed at baseline by using the REVEAL (Registry to Evaluate Early and Long-term PAH Disease Management) 2.0 risk score, are presented in the online supplement.

\section{Results}

\section{Patient Population}

Among the 2,077 patients with newly diagnosed idiopathic, heritable, or anorexigen-induced $\mathrm{PAH}$ who were enrolled in the French PH Registry between January 2006 and December 2018, 163 had a positive response to acute vasodilator testing (and subsequently received calcium-channel blockers), and 303 did not receive any $\mathrm{PAH}$ therapy within the 3 months after diagnosis (Figure 1). After the exclusion of these patients from the analysis, the study population comprised 1,611 patients: 984 (61\%) were initially treated with monotherapy, 551 (34\%) were initially treated with dual-combination therapy, and $76(5 \%)$ were initially treated with triple-combination therapy (Figure 1). Demographics and baseline characteristics of the study population are summarized in Table 1. Patients initiated on triple-combination therapy that included intravenous or subcutaneous prostacyclin were younger and had fewer comorbidities but had a greater disease severity than others (Table 1).

\section{Change in the Number of Low-Risk Variables according to Initial Treatment Strategy}

The proportion of patients with zero low-risk criteria or one low-risk criterion present at baseline was higher in patients initiated on triple-combination therapy (91\%) than in patients receiving either dual-combination therapy (72\%) or monotherapy (57\%). After a median follow-up of 5 months (IQR, 4-8 mo), $78 \%$ of patients in the triplecombination therapy group achieved three or four low-risk criteria compared with $47 \%$ of patients in the dual-combination therapy group and only $36 \%$ of those who received monotherapy initially (Figure 2).

\section{Survival Analyses}

During a median follow-up of 32 months (IQR, 15-62 mo), 508 (32\%) patients died and 65 (4\%) underwent lung transplantation. In the initial monotherapy, dualcombination therapy, and triplecombination therapy groups, 346 (35\%), 155 (28\%), and 7 (9\%) patients died and $25(3 \%)$, 29 (5\%), and 11 (14\%) patients underwent lung transplantation after a median followup of 35 months (IQR, 16-66 mo), 28 months (IQR, 12-55 mo), and 39 months (IQR, 14-78 mo), respectively. Among patients who started with monotherapy, $45 \%$ were escalated to sequential dual or triple therapy after a median time of 9 months (IQR 4-18 mo), whereas a lower proportion of patients (25\%) who received initial dual therapy were escalated to triple-combination therapy after a median time of 17 months (IQR, 7-31 mo).

Overall survival rates at $1,3,5$, and 10 years were $93 \%$ ( $95 \%$ confidence interval [CI], 91-94\%), 77\% (95\% CI, 74-79\%), 62\% (95\% CI, 59-65\%), and $44 \%$ (95\% CI, 
Table 1. Demographics and Baseline Characteristics of the Overall Study Population and according to the Initial Treatment Regimen

\begin{tabular}{|c|c|c|c|c|c|}
\hline & $\begin{array}{c}\text { Overall } \\
\text { Study } \\
\text { Population } \\
(N=1,611)\end{array}$ & $\begin{array}{l}\text { Initial } \\
\text { Monotherapy } \\
(n=984)\end{array}$ & $\begin{array}{c}\text { Initial } \\
\text { Dual- } \\
\text { Combination } \\
\text { Therapy }(n=551)\end{array}$ & $\begin{array}{c}\text { Initial } \\
\text { Triple- } \\
\text { Combination } \\
\text { Therapy }(n=76)\end{array}$ & $P$ Value \\
\hline Sex, F, $n(\%)$ & $909(56)$ & $538(55)$ & $313(57)$ & $58(77)$ & $<0.001$ \\
\hline Age, yr & $60 \pm 17$ & $63 \pm 15$ & $57 \pm 17$ & $42 \pm 17$ & $<0.001$ \\
\hline Type of $\mathrm{PAH}, n(\%)$ & & & & & $<0.001$ \\
\hline Idiopathic & $1,201(75)$ & $735(75)$ & $418(76)$ & $48(63)$ & - \\
\hline Heritable & $133(8)$ & $52(5)$ & $54(10)$ & $27(36)$ & - \\
\hline Anorexigen-induced & $277(17)$ & $197(20)$ & $79(14)$ & $1(1)$ & - \\
\hline Comorbidities, $n(\%)$ & & & & & - \\
\hline Hypertension & $798(50)$ & $524(53)$ & $259(47)$ & $15(20)$ & $<0.001$ \\
\hline Obesity & $518(32)$ & $331(34)$ & $172(31)$ & $15(20)$ & 0.037 \\
\hline Diabetes & $406(25)$ & $246(25)$ & $152(28)$ & $8(11)$ & 0.006 \\
\hline Coronary heart disease & $233(14)$ & $147(15)$ & $79(14)$ & $7(9)$ & 0.39 \\
\hline Sleep disorders & $176(11)$ & $114(12)$ & $57(10)$ & $5(7)$ & 0.34 \\
\hline Thyroid disorders & $175(11)$ & $105(11)$ & $65(12)$ & $5(7)$ & 0.37 \\
\hline Atrial fibrillation & $150(9)$ & $95(10)$ & $54(10)$ & $1(1)$ & 0.048 \\
\hline History of cancer & $112(7)$ & $67(7)$ & $44(8)$ & $1(1)$ & 0.10 \\
\hline Renal insufficiency & 79 (5) & $55(5)$ & $24(4)$ & $5(7)$ & 0.49 \\
\hline Body mass index, $\mathrm{kg} / \mathrm{m}^{2}$ & $28 \pm 9$ & $29 \pm 9$ & $28 \pm 7$ & $26 \pm 6$ & 0.015 \\
\hline NYHA functional class, $n(\%)$ & & & & & $<0.001$ \\
\hline II & $401(25)$ & $295(30)$ & $105(19)$ & $1(2)$ & - \\
\hline III & $964(60)$ & $581(59)$ & 341 (62) & $42(55)$ & - \\
\hline IV & 246 (15) & $108(11)$ & 105 (19) & $33(43)$ & - \\
\hline 6-minute-walk distance, m & $280 \pm 154$ & $286 \pm 145$ & $277 \pm 165$ & $226 \pm 179$ & 0.011 \\
\hline $\mathrm{BNP}, \mathrm{ng} \cdot \mathrm{L}^{-1}(n=855)$ & $253(100-543)$ & $205(79-430)$ & $316(134-697)$ & $404(182-585)$ & $<0.001$ \\
\hline NT-proBNP, ng $\cdot \mathrm{L}^{-1}(n=380)$ & $1,288(454-3,003)$ & $1,021(289-2,344)$ & $1,368(645-3,174)$ & $3,010(1,150-3,801)$ & $<0.001$ \\
\hline Hemodynamics & & & & & - \\
\hline Right atrial pressure, $\mathrm{mm} \mathrm{Hg}$ & $9 \pm 5$ & $9 \pm 5$ & $9 \pm 5$ & $11 \pm 6$ & $<0.001$ \\
\hline Mean pulmonary artery pressure, $\mathrm{mm} \mathrm{Hg}$ & $49 \pm 13$ & $46 \pm 11$ & $52 \pm 12$ & $63 \pm 19$ & $<0.001$ \\
\hline Pulmonary artery wedge pressure, $\mathrm{mm} \mathrm{Hg}$ & $10 \pm 4$ & $10 \pm 4$ & $9 \pm 4$ & $9 \pm 4$ & 0.001 \\
\hline Cardiac index, $\mathrm{L} \cdot \min ^{-1} \cdot \mathrm{m}^{-2}$ & $2.4 \pm 0.7$ & $2.5 \pm 0.7$ & $2.2 \pm 0.6$ & $1.8 \pm 0.5$ & $<0.001$ \\
\hline Pulmonary vascular resistance, Wood units & $10 \pm 5$ & $9 \pm 4$ & $12 \pm 5$ & $19 \pm 7$ & $<0.001$ \\
\hline $\mathrm{Sv}_{\mathrm{O} 2}, \%(n=832)$ & $61 \pm 11$ & $63 \pm 10$ & $60 \pm 11$ & $53 \pm 11$ & $<0.001$ \\
\hline Risk status, $n(\%)$ & & & & & $<0.001$ \\
\hline Low risk & $234(15)$ & $178(18)$ & $56(10)$ & 0 & - \\
\hline Intermediate risk & $1,134(70)$ & $714(73)$ & $382(69)$ & $38(50)$ & - \\
\hline High risk & $243(15)$ & $92(9)$ & $113(21)$ & $38(50)$ & - \\
\hline
\end{tabular}

Definition of abbreviations: BNP = brain natriuretic peptide; IQR = interquartile range; NT-proBNP = N-terminal pro-BNP; NYHA = New York Heart Association; $\mathrm{PAH}=$ pulmonary arterial hypertension; $\mathrm{Sv}_{\mathrm{O}_{2}}=$ mixed venous oxygen saturation .

Data are presented as the mean \pm SD or median (IQR) unless otherwise specified.

${ }^{*}$ ANOVA (comparison among treatment regimen groups).

41-49\%), respectively (Figure $3 \mathrm{~A}$ ). In the overall population, survival was significantly better in patients who received triplecombination therapy ( $91 \%$ at $5 \mathrm{yr}$ ) than in patients initiated on dual-combination therapy or monotherapy ( $61 \%$ at $5 \mathrm{yr}$ ) $(P<0.001)$ (Figure 3B). When actual survival was compared with predicted survival (according to the French equation), an improvement in outcomes was observed, irrespective of initial treatment strategy (see Figure E1 in the online supplement).

Transplant-free survival rates were $92 \%$, $74 \%, 59 \%$, and $39 \%$ at $1,3,5$, and 10 years, respectively (Figure 4A). Transplant-free survival was also better in patients initiated on triple-combination therapy, who had a 5-year survival rate of $75 \%$ compared with patients receiving initial dual-combination therapy and monotherapy, who had 5-year survival rates of $56 \%$ and $58 \%$, respectively $(P=0.038$; Figure $4 \mathrm{~B})$.

In univariable analysis, the following were associated with survival (Table 2): female sex, age, type of $\mathrm{PAH}$, year of diagnosis, NYHA FC, 6MWD, right atrial pressure, mean pulmonary arterial pressure, cardiac index, mixed venous oxygen saturation, $\mathrm{BNP}<50 \mathrm{ng} \cdot \mathrm{L}^{-1}$ or NT-proBNP $<300 \mathrm{ng} \cdot \mathrm{L}^{-1}$, and initial triple-combination therapy that included intravenous or subcutaneous prostacyclin. Because initial treatment strategies changed over time and the proportion of patients initiated on combination therapy increased after 2014, only the initial treatment regimen was included in the multivariable model. In the multivariable analysis, only female sex, younger age, a higher baseline 6MWD, and initial triple-combination therapy were independently associated with a reduced risk of death (Table 2).

After propensity risk matching of age, sex, and PVR measured at baseline, 73 patients of the initial triple-combination therapy group were matched with 73 patients initiated on dual-combination therapy ( $77 \%$ female in each group; mean age, $42 \pm 17 \mathrm{yr}$ in both groups; PVR values of $19 \pm 7 \mathrm{WU}$ and $18 \pm 6 \mathrm{WU}$ in the triple-combination group and the dual-combination group, 
BASELINE

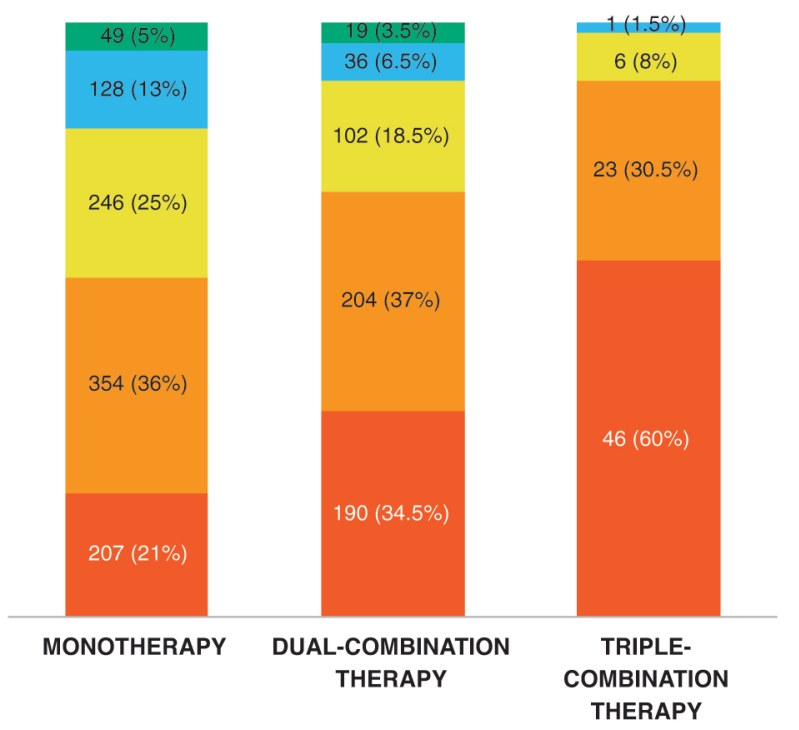

FIRST FOLLOW-UP

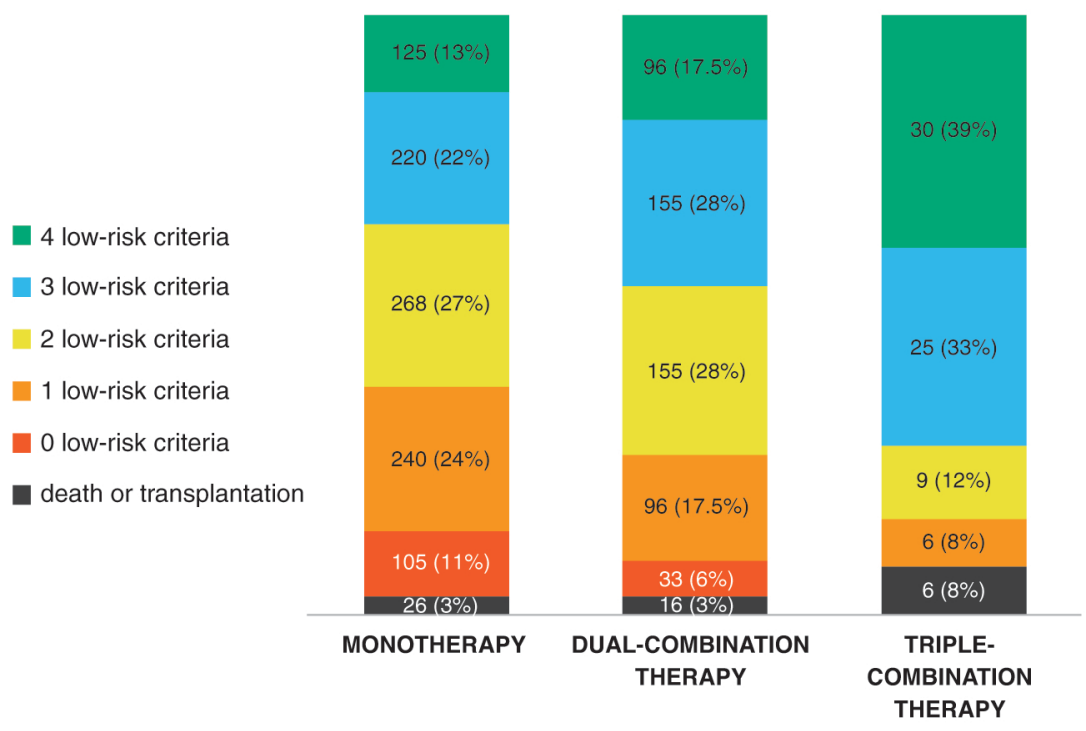

Figure 2. Number of low-risk criteria present at baseline or achieved at first follow-up according to the initial treatment regimen (monotherapy, dual-combination therapy, or triple-combination therapy). The first follow-up visit occurred 5 months (interquartile range, 4-8) after diagnosis. Low-risk criteria were as follows: New York Heart Association functional class of I or II, 6-minute-walk distance of $>440 \mathrm{~m}$, right atrial pressure of $<8 \mathrm{~mm} \mathrm{Hg}$, and cardiac index of $\geqslant 2.5 \mathrm{~L} \cdot \mathrm{min}^{-1} \cdot \mathrm{m}^{-2}(1,2,14)$.

respectively; Table E1). Kaplan-Meier overall survival estimates in the propensity score-matched patients within the triplecombination group and dual-combination group are presented in Figure 5A. Survival rates at $1,3,5$, and 10 years were $94 \%(95 \%$ CI, $89-100 \%$ ), 90\% (95\% CI, 83-98\%), 90\% (95\% CI, 83-98\%), and 85\% (95\% CI, 74-98\%) in the matched triple-combination group and $96 \%$ (95\% CI, 91-100\%), $82 \%$ (95\% CI, 73-92\%), 75\% (95\% CI, 64-88\%), and $65 \%(95 \% \mathrm{CI}, 51-84 \%)$ in the matched dual-combination group, respectively $(P=0.04)$. In these matched patients, there was a trend for better transplant-free survival in patients initiated on triple-combination therapy $(P=0.086$; Figure $5 B)$. Kaplan-Meier survival estimates in the propensity score-matched patients within the dualcombination group and monotherapy group are presented in Figure 5C. The two samples $(n=516$ in each group; Table E2) were matched on the basis of sex (56\% female in each group), age ( $57 \pm 17 \mathrm{yr}$ and $59 \pm 16 \mathrm{yr}$ in the dual-combination group and monotherapy group, respectively), and PVR $(12 \pm 5 \mathrm{WU}$ and $11 \pm 5 \mathrm{WU}$ in the dualcombination group and monotherapy group, respectively). Survival rates at 1, 3, 5, and 10 years were 93\% (95\% CI, 91-95\%), 77\% (95\% CI, 72-81\%), 61\% (95\% CI, 56-67\%), and $43 \%(95 \% \mathrm{CI}, 33-55 \%)$ in the matched dual-combination group and $92 \%$ (95\% CI,
90-94\%), 77\% (95\% CI, 73-81\%), 66\% (95\% CI, $61-71 \%$ ), and $48 \%$ (95\% CI, $42-44 \%$ ) in the matched monotherapy group,

respectively $(P=0.33)$.

Patient dispositions according to the ESC/ERS PH Guidelines risk status at baseline are shown in Figure E2. Among the 243 (15\%) patients with baseline high risk, the survival of those who received initial triple-combination therapy that included intravenous or subcutaneous prostacyclin was significantly better than that of patients initiated on another treatment regimen $(P<0.001)$, whereas there was no difference in survival between high-risk patients who received monotherapy and those who received dual-combination therapy (Figure $6 \mathrm{~A})$. In patients at intermediate risk $(n=1,134,70 \%)$, initial triple-combination therapy was associated with a significant survival benefit over dual-combination therapy and monotherapy $(P<0.001)$. In this group of patients at intermediate risk, initial dual-combination therapy conferred a survival benefit over monotherapy $(P=0.025)$ (Figure 6B). In patients at low risk $(n=234,15 \%)$, no difference was observed between the initial dual-combination therapy group and the initial monotherapy group $(P=0.23)$ (Figure 6C). Similar results were observed when the REVEAL 2.0 risk score was used to determine the risk status (online supplement).

\section{Subgroup of Patients Initiated on Parenteral Prostacyclin}

In the subgroup of 148 patients who were initiated on intravenous or subcutaneous prostacyclin, 134 received intravenous epoprostenol, 12 received subcutaneous treprostinil, and 2 received intravenous treprostinil. Thirty-one patients were started on monotherapy, 41 received a combination of prostacyclin and one oral drug, and 76 received triple-combination therapy (Table E3). There was no difference among the three treatment groups in terms of age, sex, the etiology of PAH, the NYHA FC, the $6 \mathrm{MWD}$, or biomarkers. Only the hemodynamics differed slightly, with the monotherapy subgroup having a less severe status than the other treatment subgroups (Table E3). The overall survival of patients on prostacyclin was similar to that observed in the overall population, and although no difference between the monotherapy subgroup and the dual-combination therapy subgroup was shown, there was a significantly higher survival rate among patients who received initial triplecombination therapy $(P=0.037$; Figure 7$)$.

\section{Discussion}

In our large cohort of patients with newly diagnosed idiopathic, heritable, or 
Patients, at risk (n)

Overall survival $95 \% \mathrm{Cl}$

\section{B}

Patients, at risk (n)

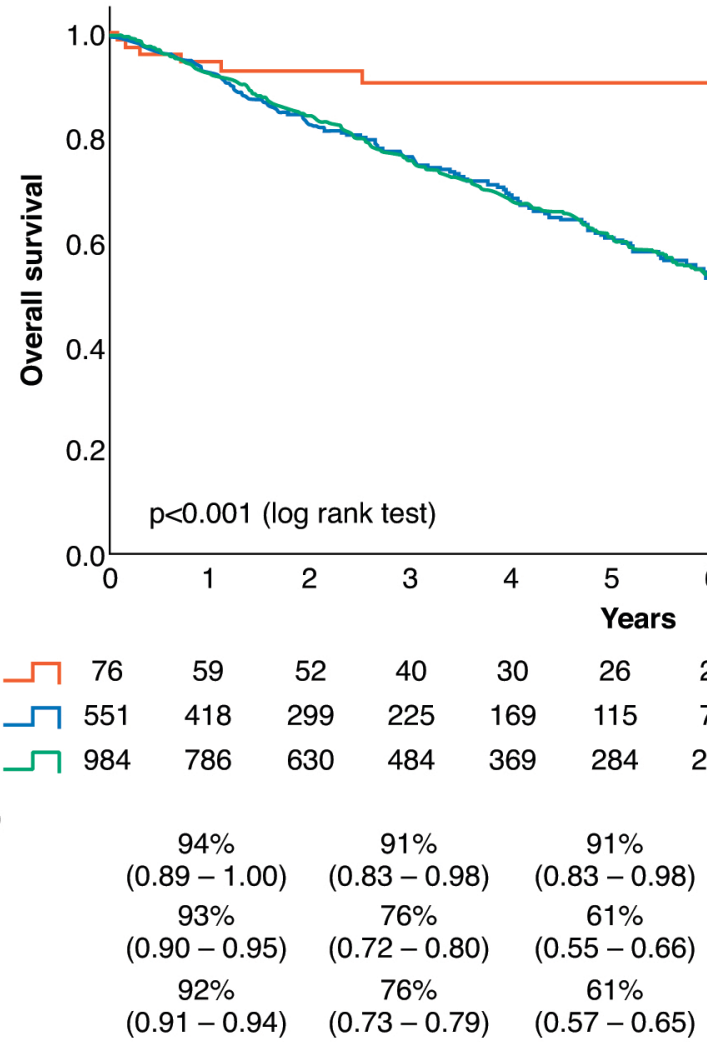

Overall survival $(95 \% \mathrm{Cl})$

Triple combo

Dual combo

Monotherapy

$0.73-0.79)$

$(0.57-0.65)$

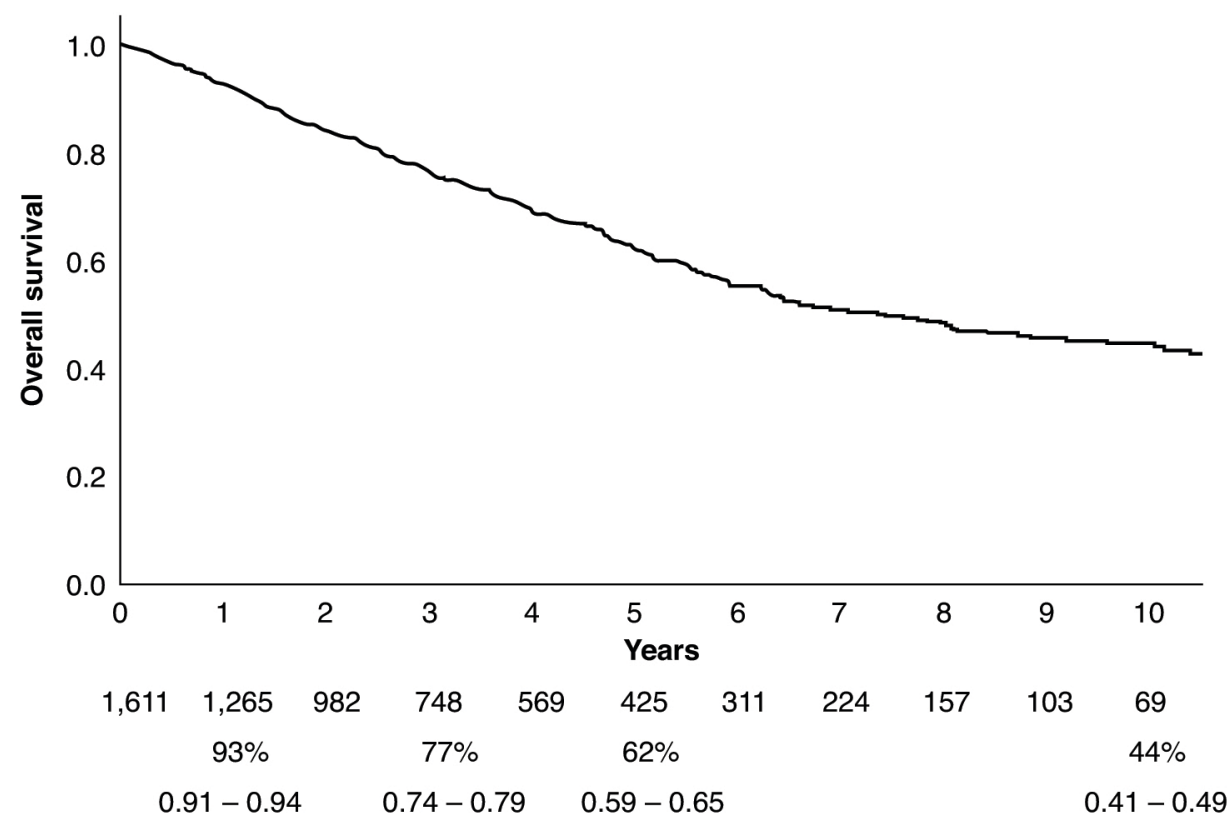

$\begin{array}{rccccccccccc}\text { Triple combo }-\curvearrowleft & 76 & 59 & 52 & 40 & 30 & 26 & 22 & 17 & 10 & 6 & 1 \\ \text { Dual combo }-\curvearrowleft & 551 & 418 & 299 & 225 & 169 & 115 & 79 & 46 & 24 & 12 & 7 \\ \text { Monotherapy }-\curvearrowleft & 984 & 786 & 630 & 484 & 369 & 284 & 210 & 161 & 123 & 85 & 61\end{array}$

Figure 3. Kaplan-Meier overall survival estimates $(A)$ in the study population and $(B)$ according to the initial treatment strategy. $\mathrm{Cl}=\mathrm{confidence}$ interval; combo = combination therapy.

anorexigen-induced PAH, long-term survival was independently related to the initial treatment strategy. Initial triplecombination therapy that included parenteral prostacyclin was associated with a higher overall survival rate than monotherapy or dual-combination therapy, with or without parenteral prostacyclin. In addition, initial dual-combination therapy was associated with a higher survival rate than monotherapy in patients who were at intermediate risk at diagnosis. 


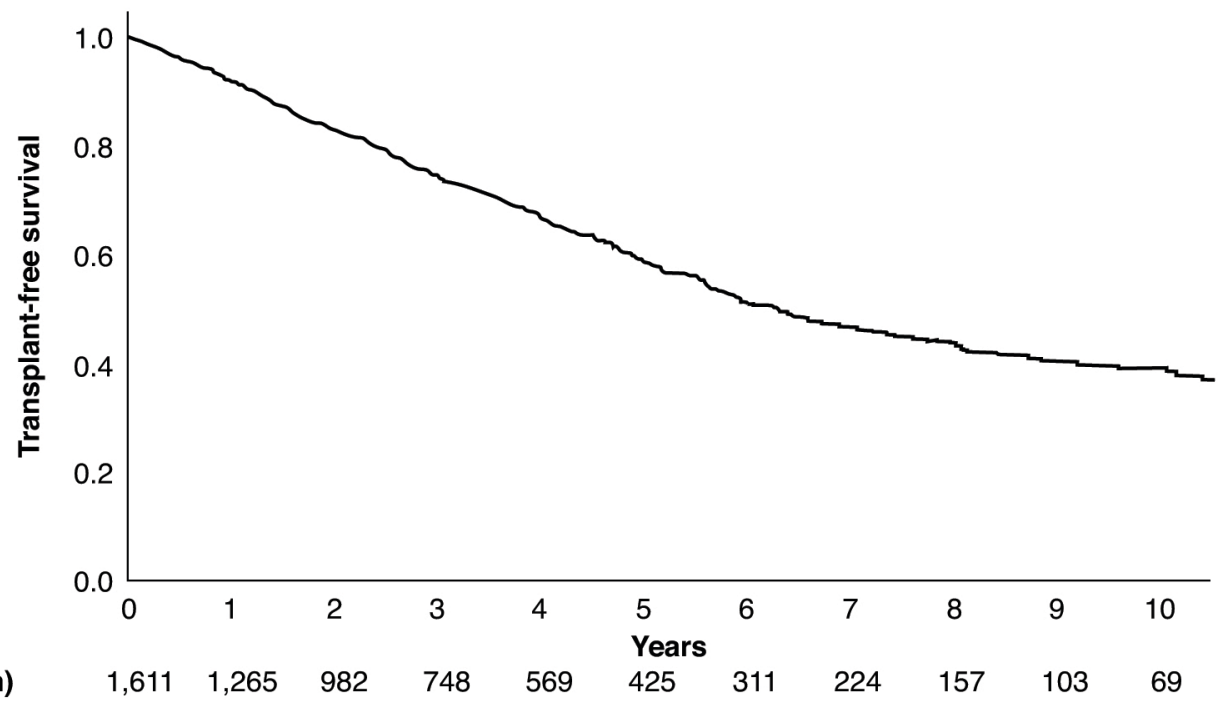

B

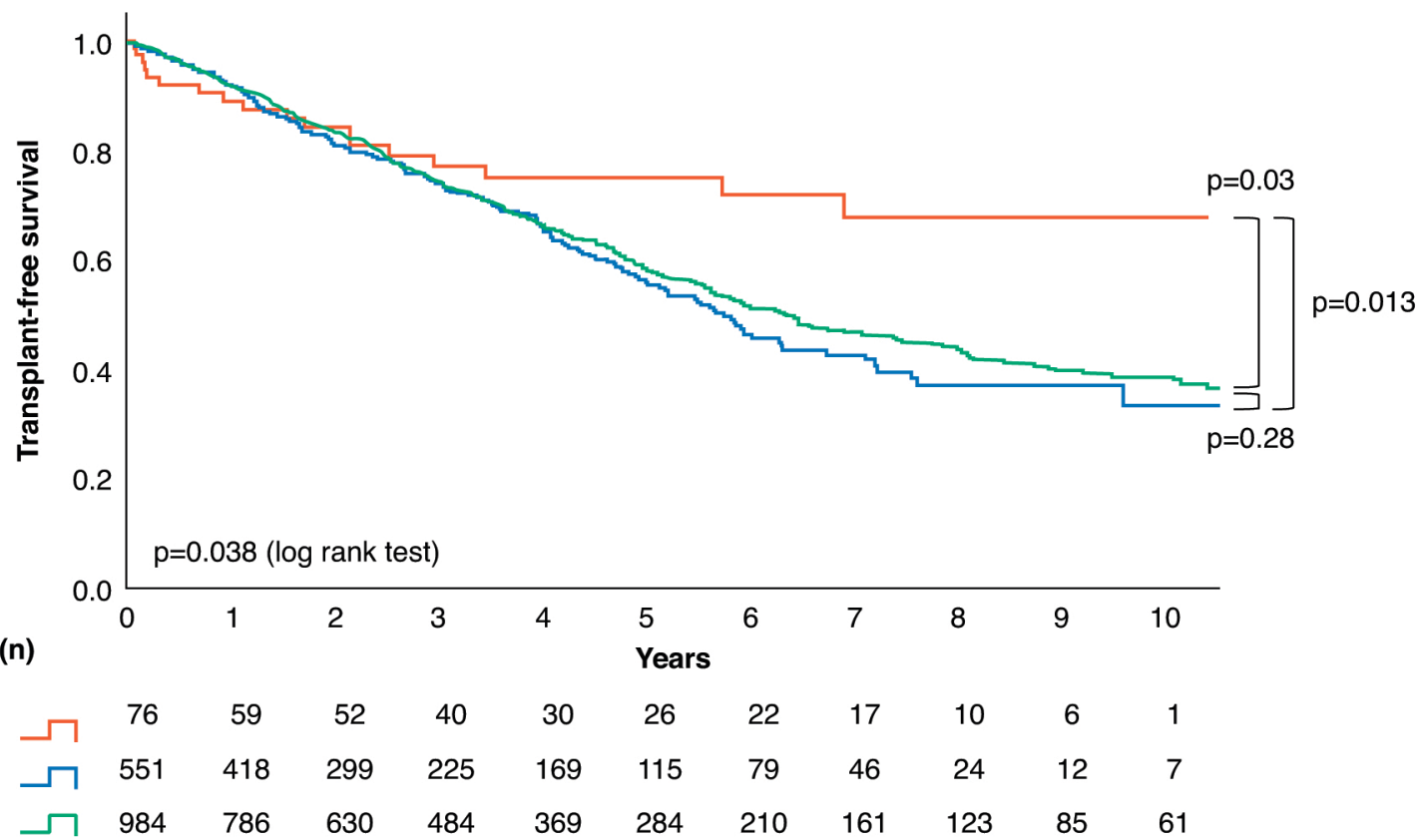

Figure 4. Kaplan-Meier transplant-free survival estimates $(A)$ in the study population and $(B)$ according to the initial treatment strategy. Transplant-free survival estimates at 1,3,5, and 10 years were $(A) 92 \%, 74 \%, 59 \%$, and $39 \%$ in the overall study population and were (B) 89\%, $77 \%, 75 \%$, and $68 \%$ in the triple-combination therapy group (red line); $92 \%, 74 \%, 56 \%$, and $34 \%$ in the dual therapy group (blue line); and $92 \%, 74 \%, 58 \%$, and $39 \%$ in the monotherapy group (green line), respectively. combo = combination therapy.

In our study, initial triple therapy led to a higher overall survival rate than initial dual therapy or monotherapy, despite a greater disease severity being present in patients initiated on triple therapy. Importantly, similar results were observed for transplantfree survival, indicating that the higher proportion of transplantations in the triple therapy group did not significantly bias the overall survival analysis. The younger age of the patients initiated on triple therapy could also have contributed to their higher survival rate. However, we showed that age and initial triple-combination therapy were independently associated with a higher survival rate. After matching for age, sex, and PVR in a propensity score analysis to correct for these confounding factors, initial triple-combination therapy was also associated with a significant survival benefit over initial dual-combination therapy. An RCT is needed to definitively answer the question of whether triple therapy is superior to other strategies. However, altogether, these results support the use of initial combination therapy that includes parenteral prostacyclin in younger patients in the highest-risk group with the most severe disease. We also provide the first data that a triplecombination approach that includes parenteral prostacyclin might be beneficial in intermediate-risk patients, which may help support clinical decisionmaking in the absence of randomized trial data.

The proportion of patients who achieved three or four of the low-risk-status criteria at the first follow-up evaluation 
Table 2. Univariable and Multivariable Analyses Relating Survival Time to Selected Baseline Variables

\begin{tabular}{|c|c|c|c|c|c|c|}
\hline \multirow[b]{2}{*}{ Variable } & \multicolumn{3}{|c|}{ Univariable Analysis } & \multicolumn{3}{|c|}{ Multivariable Analysis } \\
\hline & HR & $95 \% \mathrm{Cl}$ & $P$ Value & HR & $95 \% \mathrm{Cl}$ & $P$ Value \\
\hline Sex, F & 0.545 & $0.457-0.650$ & 0.0001 & 0.522 & $0.405-0.672$ & 0.0001 \\
\hline Age, per yr & 1.052 & $1.045-1.059$ & 0.0001 & 1.037 & $1.026-1.048$ & 0.0001 \\
\hline Heritable PAH vs. idiopathic PAH or anorexigen-induced PAH & 0.146 & $0.075-0.283$ & 0.0001 & - & - & - \\
\hline Year of diagnosis & 0.936 & $0.906-0.968$ & 0.0001 & - & - & - \\
\hline NYHA FC IV vs. FC II or III & 2.138 & $1.725-2.648$ & 0.0001 & 1.311 & $0.937-1.834$ & 0.115 \\
\hline 6MWD, per m & 0.996 & $0.995-0.996$ & 0.0001 & 0.996 & $0.995-0.998$ & 0.0001 \\
\hline RAP, per mm Hg & 1.028 & $1.011-1.046$ & 0.002 & 1.010 & $0.982-1.038$ & 0.504 \\
\hline $\mathrm{mPAP}$, per mm Hg & 0.986 & $0.979-0.993$ & 0.0001 & 1.000 & $0.990-1.011$ & 0.944 \\
\hline PAWP, per $\mathrm{mm} \mathrm{Hg}$ & 1.018 & $0.996-1.040$ & 0.11 & 0.969 & $0.935-1.004$ & 0.082 \\
\hline Cardiac index, per $\mathrm{L} \cdot \mathrm{min}^{-1} \cdot \mathrm{m}^{-2}$ & 0.803 & $0.698-0.925$ & 0.002 & 0.905 & $0.728-1.127$ & 0.373 \\
\hline PVR, per Wood unit & 0.993 & $0.974-1.012$ & 0.46 & - & - & - \\
\hline $\mathrm{Sv}_{\mathrm{O} 2}$, per \% & 0.965 & $0.953-0.977$ & 0.0001 & - & - & - \\
\hline BNP $<50 \mathrm{ng} \cdot \mathrm{L}^{-1}$ or NT-proBNP $<300 \mathrm{ng} \cdot \mathrm{L}^{-1}$ & 0.445 & $0.304-0.651$ & 0.0001 & 0.664 & $0.420-1.050$ & 0.080 \\
\hline Initial triple therapy vs. monotherapy or dual therapy & 0.250 & $0.118-0.527$ & 0.0001 & 0.289 & $0.105-0.801$ & 0.017 \\
\hline
\end{tabular}

Definition of abbreviations: $6 \mathrm{MWD}=6$-minute-walk distance; $\mathrm{BNP}=$ brain natriuretic peptide; $\mathrm{Cl}=\mathrm{confidence}$ interval; $\mathrm{FC}=$ functional class; $\mathrm{HR}=$ hazard ratio; mPAP = mean pulmonary arterial pressure; NT-proBNP = N-terminal pro-BNP; NYHA = New York Heart Association;

$\mathrm{PAH}=$ pulmonary arterial hypertension; $\mathrm{PAWP}=$ pulmonary artery wedge pressure; $\mathrm{PVR}=$ pulmonary vascular resistance; RAP $=$ right atrial pressure; $\mathrm{Sv}_{\mathrm{O} 2}=$ mixed venous oxygen saturation.

increased with the number of medications initiated. The triple therapy group included the highest proportion of patients who had three or four low-risk criteria and the best survival. This observation supports previous findings that achieving a low-risk status at follow-up may translate to better long-term outcomes (12-18).

For patients at intermediate risk at diagnosis, we showed that initial doublecombination therapy was associated with a higher long-term survival rate over monotherapy, despite a greater disease severity at diagnosis being present in patients who received two medications up front. In the AMBITION RCT, there was a $50 \%$ reduction in the risk of a clinical failure event in treatment-naive patients with $\mathrm{PAH}$ who were initiated on dual oral combination therapy (ambrisentan and tadalafil) compared with those who were initiated on monotherapy (8). Similarly, in a post hoc analysis of the AMBITION trial, initial combination therapy led to better outcomes, irrespective of the baseline REVEAL risk status (19). However, there was no clear demonstration of improved survival in patients who received initial combination therapy in the AMBITION trial (9). In our study, there was also no difference between initial doublecombination therapy and initial monotherapy in terms of overall survival in the whole population (Figure 3B, Figure $5 \mathrm{C})$. However, in patients at intermediate risk at diagnosis, the survival rate was higher in those who received initial dualcombination therapy than in those initiated on monotherapy. Of note, there were more patients who had their therapy escalated in the monotherapy group than in the dual therapy group, which may have improved survival in the initial monotherapy group.

In our study, initial triple-combination therapy that included parenteral prostacyclin was associated with a survival benefit when compared with dualcombination therapy or monotherapy. Transplant-free survival was also higher in the triple-combination group; this result may be more generalizable to healthcare systems in which highly urgent lung transplantation allocation for patients with $\mathrm{PAH}$ is unavailable. Continuous intravenous epoprostenol is the only $\mathrm{PAH}$ therapy with a survival benefit for patients with $\mathrm{PAH}$ that has been demonstrated in a single RCT (20) and confirmed in long-term observational studies $(21,22)$. To explore whether the survival benefit observed with triplecombination therapy was due to the use of parenteral prostacyclin itself or its combination with other treatments, we performed survival analysis in the subgroup of patients started on parenteral prostacyclin, divided according to prostacyclin monotherapy, dual therapy, or triple-combination therapy. We observed results similar to those seen in the overall population: the survival rate of patients initiated on initial triple-combination therapy was higher than that of patients started with other treatment regimens with parenteral prostacyclin. This finding supports the importance of targeting three pathways of endothelial dysfunction: the prostacyclin, nitric oxide, and ET-1 (endothelin 1) pathways. In PAH, there is a reduction in pulmonary vasodilatory and antiproliferative factors, such as prostacyclin and nitric oxide, whereas vasoconstrictors (also promoting cell proliferation) such as ET-1 are upregulated $(23,24)$. Targeting all three dysfunctional pathways together might prevent the upregulation of other pathways not targeted by initial monotherapy or a dual-combination treatment regimen. Of note, the recently presented results of the TRITON (Efficacy and Safety of Initial Triple versus Initial Dual Oral Combination Therapy in Patients with Newly Diagnosed Pulmonary Arterial Hypertension) study do not suggest that the oral prostacyclin receptor agonist selexipag behaves like parenteral prostacyclin, with broadly similar hemodynamic and clinical results at 6 months between patients treated with initial oral double-combination therapy and those treated with triple-combination therapy being shown (25). Importantly, the TRITON study did not include patients with FC IV disease, who are at the highest risk, and did not evaluate parenteral prostacyclin as a component of triple therapy. Thus, the 
A

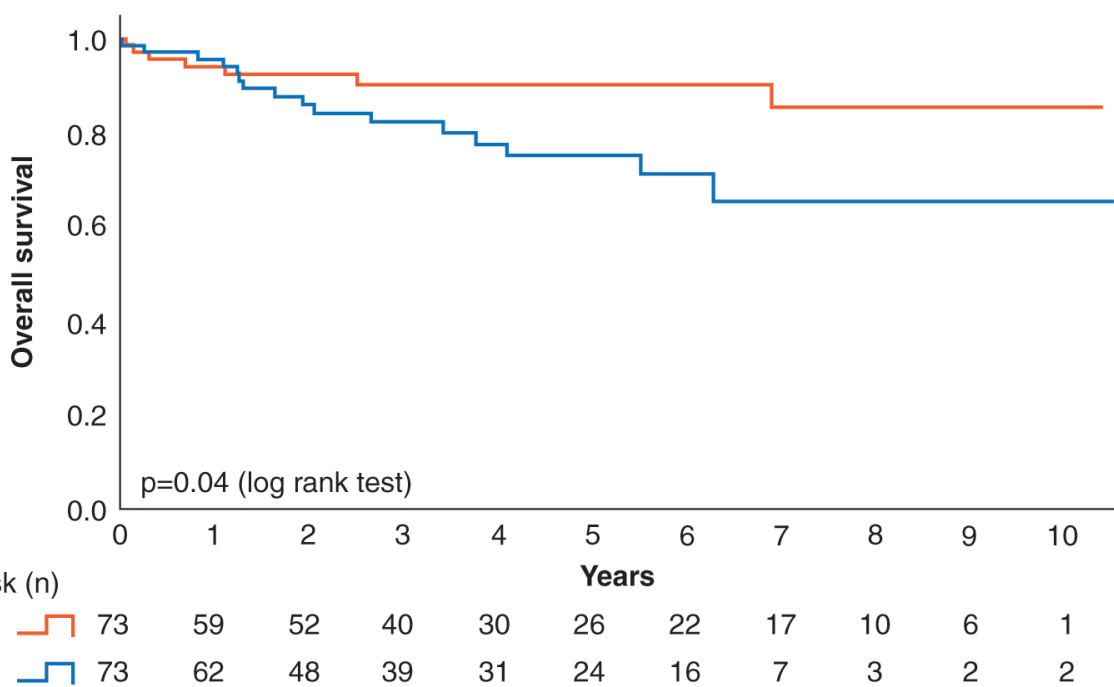

B

Patients, at risk (n)

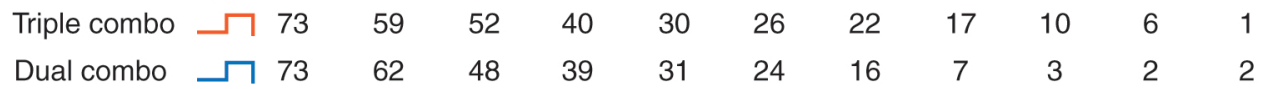

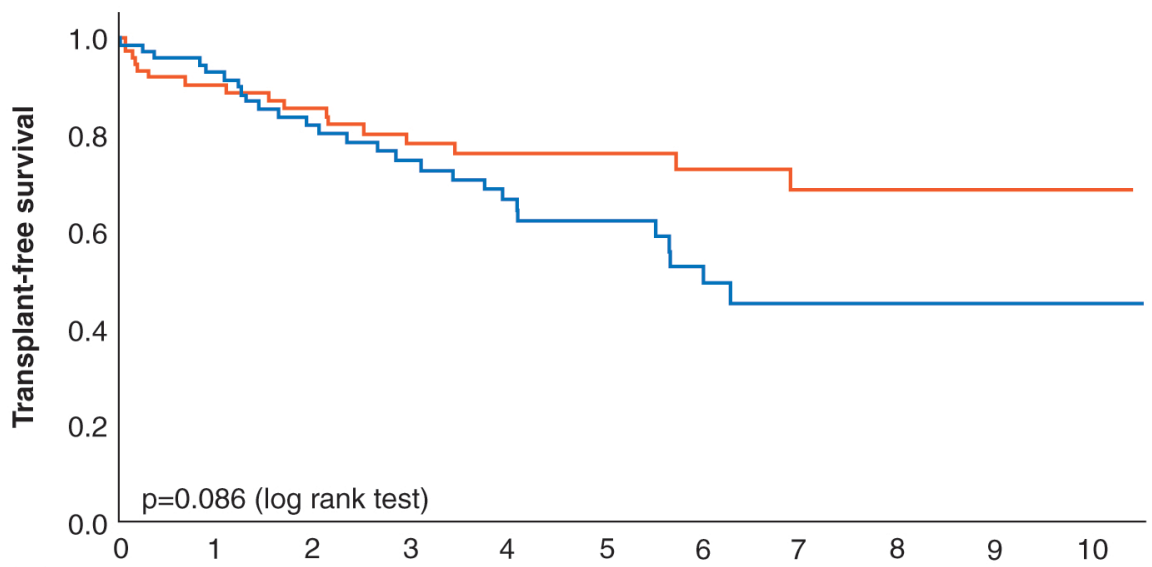

Patients, at risk (n)

Years

$\begin{array}{llllllllllll}\text { Triple combo }-\neg & 73 & 59 & 52 & 40 & 30 & 26 & 22 & 17 & 10 & 6 & 1 \\ \text { Dual combo } \neg & 73 & 62 & 48 & 39 & 31 & 24 & 16 & 7 & 3 & 2 & 2\end{array}$

C

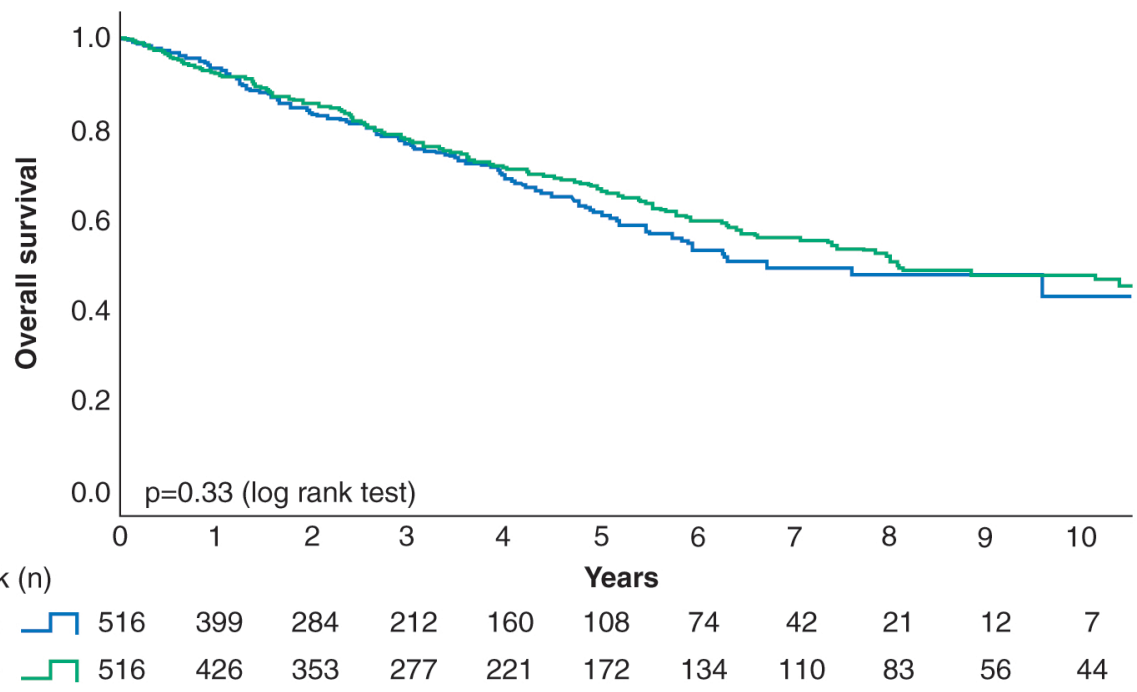

Figure 5. Kaplan-Meier survival estimates according to initial treatment strategy in the propensity score-matched patients. $(A)$ Overall survival and $(B)$ transplant-free survival in the initial triple-combination group versus the initial dual-combination group. (C) Overall survival in the initial dual-combination group versus the initial monotherapy group. combo=combination therapy. 
A

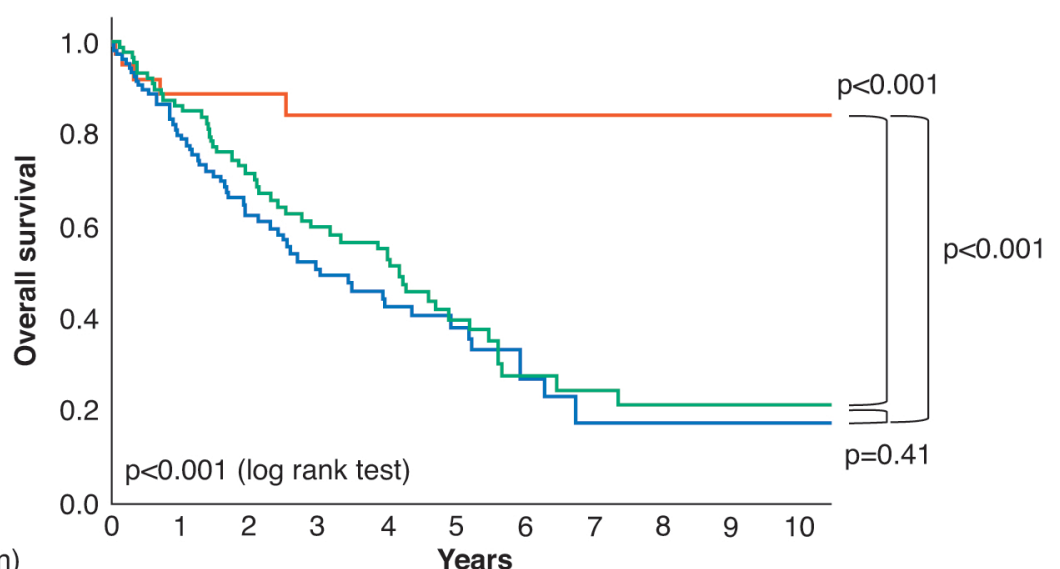

Patients, at risk (n)

$\begin{array}{llllllllllll}\text { Triple combo } \_ \text {_ } & 38 & 27 & 24 & 17 & 13 & 12 & 10 & 9 & 5 & 3 & 1\end{array}$

Dual combo $\_\begin{array}{lllllllllll}113 & 71 & 48 & 33 & 24 & 16 & 8 & 3 & 2 & 1 & 1\end{array}$

$\begin{array}{llllllllllll}\text { Monotherapy }-\neg & 92 & 69 & 49 & 38 & 30 & 19 & 10 & 8 & 6 & 3 & 3\end{array}$

B

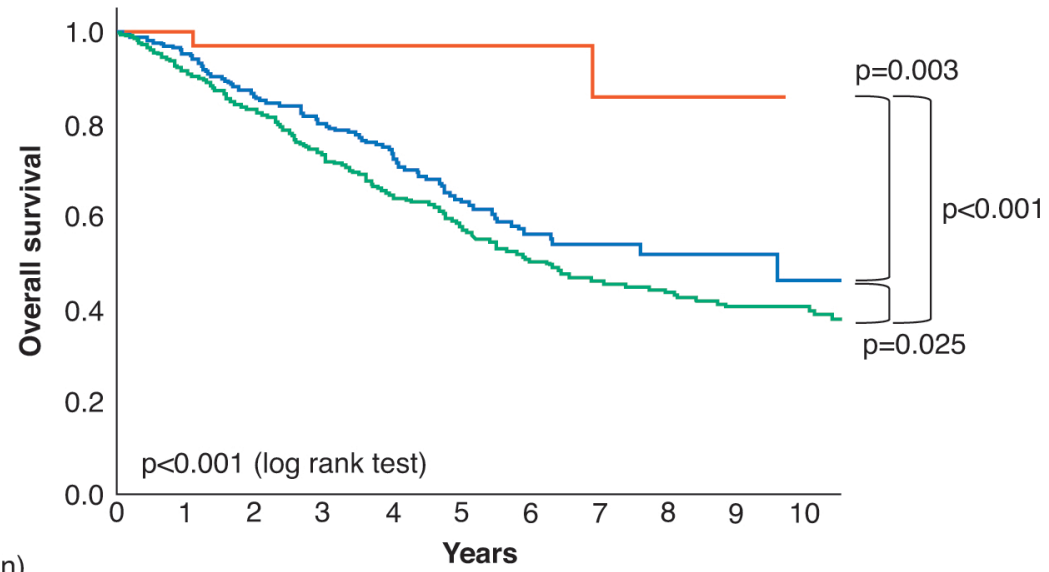

Patients, at risk (n)

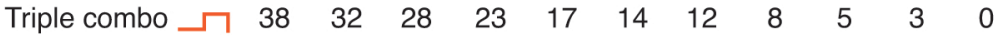

Dual combo _ـ $\begin{array}{lllllllllll}382 & 301 & 214 & 160 & 122 & 83 & 59 & 38 & 21 & 10 & 6\end{array}$

Monotherapy $ـ \begin{array}{lllllllllll}714 & 560 & 454 & 340 & 257 & 199 & 144 & 113 & 86 & 61 & 46\end{array}$

\section{C}

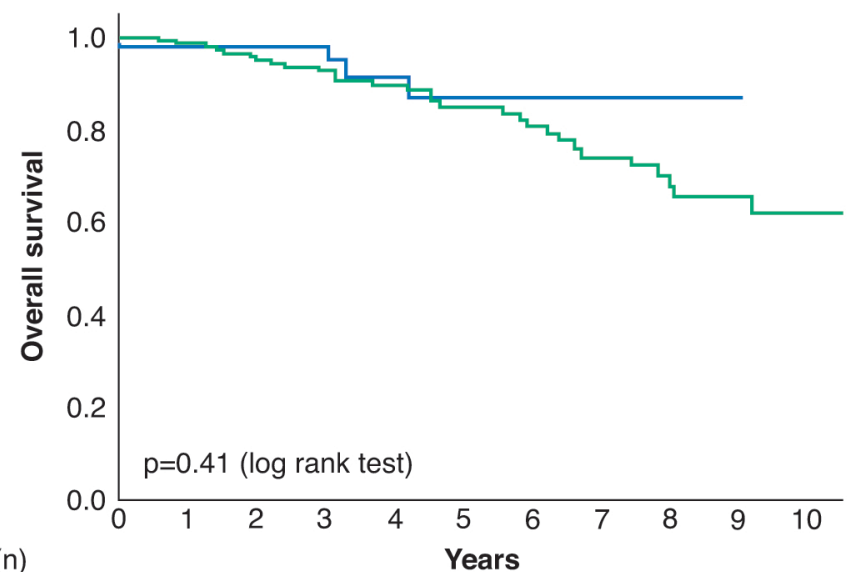

Patients, at risk (n)

Years

$\begin{array}{cccccccccccc}\text { Dual combo } \neg & 56 & 46 & 37 & 32 & 23 & 16 & 12 & 5 & 1 & 1 & 0 \\ \text { Monotherapy } \neg & 178 & 157 & 127 & 106 & 82 & 66 & 56 & 40 & 31 & 21 & 12\end{array}$

Figure 6. Kaplan-Meier survival estimates according to the initial treatment strategy and baseline risk status according to Swedish Pulmonary Arterial Hypertension Register (SPAHR) and/or Comparative, Prospective Registry of Newly Initiated Therapies for Pulmonary Hypertension (COMPERA) methodology $(12,13)$. (A) Patients with a high-risk status, $(B)$ patients with an intermediate-risk status, and $(C)$ patients with a lowrisk status. combo $=$ combination therapy. 


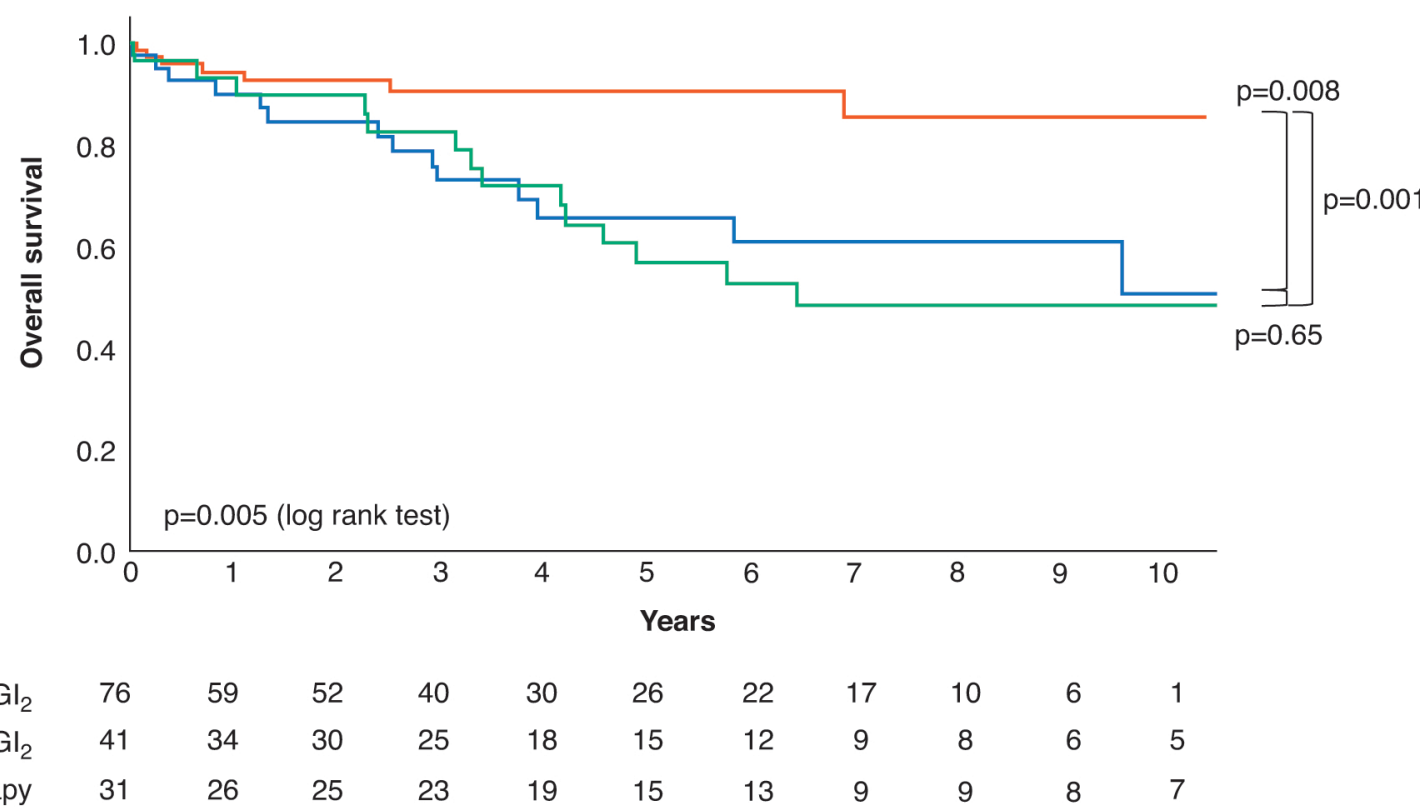

Figure 7. Kaplan-Meier survival estimates according to treatment strategy in the subgroup of patients who received continuous intravenous or subcutaneous infusion of prostacyclin in their initial treatment regimen $(n=148)$. Patients initiated on triple-combination therapy had a significantly higher survival rate than those receiving either dual-combination therapy or monotherapy with intravenous or subcutaneous prostacyclin. combo = combination therapy; incl. = including; $\mathrm{PGI}_{2}=$ intravenous or subcutaneous prostacyclin.

results of the TRITON study do not refute the results of our study and suggest, rather, that further long-term trials of therapeutic strategies are needed.

A strength of our study is the long follow-up, the large size of our cohort, and the high number of events, which allowed for a robust multivariable survival analysis. Nevertheless, there are limitations to our study. First, it is a retrospective analysis of prospectively recruited patients with $\mathrm{PAH}$ during a relatively long period of time during which the guidelines for the diagnosis and treatment of PAH changed, reflecting a better understanding of the disease and its management $(1,2,26,27)$. However, our registry recruited a large number of patients treated with different strategies during the same period, allowing for a careful comparison of treatment strategies in a multicenter national network of expert centers. Nevertheless, the choice of initial treatment strategy was at the discretion of the treating physician, and there was no standardization of the protocols, which is a limitation. In addition, we were not able to account for all changes in supportive and general medical care over this time period, which is also a limitation. Second, this study did not evaluate patients with associated conditions such as systemic sclerosis or portal hypertension. We believe that focusing on idiopathic, heritable, and anorexigen-induced $\mathrm{PAH}$ allowed us to study a population in whom survival and outcomes are less influenced by the direct consequence of the associated conditions. More data are needed to confirm that our findings are similar for $\mathrm{PAH}$ associated with other conditions, even though the results obtained in idiopathic $\mathrm{PAH}$ are usually broadly confirmed in associated forms $(17,28)$. Finally, although we accounted for known confounding factors associated with treatment strategy selection by using a multivariable Cox model and a propensity risk-matching analysis, the inequalities in patient characteristics among treatment groups raise the possibility of residual confounding, which is a limitation. Conclusive evidence of improved survival with triple therapy would require a prospective randomized trial to eliminate the effect of measured and unmeasured confounders. Even though we performed analyses that adjusted for age, sex, and the severity of hemodynamic status, triplecombination therapy may not be as effective or as tolerated among older patients with PAH who have multiple comorbidities.
In conclusion, this study supports the utility of multidimensional risk stratification to choose the most appropriate initial treatment strategy for patients with newly diagnosed PAH. Initial triple-combination therapy that includes parenteral prostacyclin is associated with a higher long-term survival rate for the patients with the most severe cases of idiopathic, heritable, or anorexigen-induced PAH. For patients at intermediate risk at diagnosis, dual-combination therapy is associated with a higher survival rate than monotherapy. Although randomized trials are needed to conclusively evaluate the efficacy of triple therapy, these findings provide new evidence to support the $\mathrm{PAH}$ treatment algorithm presented in the ESC/ERS PH guidelines and at the Sixth World Symposium on PH $(1,2)$.

Acknowledgment: The authors thank Laurence Rottat (Hôpital Bicêtre, Assistance Publique-Hôpitaux de Paris, Le KremlinBicêtre, France) for her work in the data management of the French registry. The authors also thank all contributors to the French $\mathrm{PH}$ Network and Registry. 


\section{References}

1. Galiè N, Humbert M, Vachiery J-L, Gibbs S, Lang I, Torbicki A, et al. 2015 ESC/ERS guidelines for the diagnosis and treatment of pulmonary hypertension: the Joint Task Force for the Diagnosis and Treatment of Pulmonary Hypertension of the European Society of Cardiology (ESC) and the European Respiratory Society (ERS): Endorsed by: Association for European Paediatric and Congenital Cardiology (AEPC), International Society for Heart and Lung Transplantation (ISHLT). Eur Respir J 2015; 46:903-975.

2. Galiè N, Humbert M, Vachiery J-L, Gibbs S, Lang I, Torbicki A, et al.; ESC Scientific Document Group. 2015 ESC/ERS guidelines for the diagnosis and treatment of pulmonary hypertension: the Joint Task Force for the Diagnosis and Treatment of Pulmonary Hypertension of the European Society of Cardiology (ESC) and the European Respiratory Society (ERS): Endorsed by: Association for European Paediatric and Congenital Cardiology (AEPC), International Society for Heart and Lung Transplantation (ISHLT). Eur Heart J 2016;37:67-119.

3. Galiè N, Channick RN, Frantz RP, Grünig E, Jing ZC, Moiseeva O, et al. Risk stratification and medical therapy of pulmonary arterial hypertension. Eur Respir J 2019;53:1801889.

4. Humbert M, Barst RJ, Robbins IM, Channick RN, Galiè N, Boonstra A, et al. Combination of bosentan with epoprostenol in pulmonary arterial hypertension: BREATHE-2. Eur Respir J 2004;24:353-359.

5. Kemp K, Savale L, O'Callaghan DS, Jaïs X, Montani D, Humbert M, et al. Usefulness of first-line combination therapy with epoprostenol and bosentan in pulmonary arterial hypertension: an observational study. $J$ Heart Lung Transplant 2012;31:150-158.

6. Sitbon O, Jaïs X, Savale L, Cottin V, Bergot E, Macari EA, et al. Upfront triple combination therapy in pulmonary arterial hypertension: a pilot study. Eur Respir J 2014;43:1691-1697.

7. D'Alto M, Badagliacca R, Argiento P, Romeo E, Farro A, Papa S, et al. Risk reduction and right heart reverse remodeling by upfront triple combination therapy in pulmonary arterial hypertension. Chest 2020;157: 376-383.

8. Galiè N, Barberà JA, Frost AE, Ghofrani H-A, Hoeper MM, McLaughlin VV, et al.; AMBITION Investigators. Initial use of ambrisentan plus tadalafil in pulmonary arterial hypertension. N Engl J Med 2015;373:834-844.

9. Hoeper MM, McLaughlin VV, Barberá JA, Frost AE, Ghofrani H-A, Peacock AJ, et al. Initial combination therapy with ambrisentan and tadalafil and mortality in patients with pulmonary arterial hypertension: a secondary analysis of the results from the randomised, controlled AMBITION study. Lancet Respir Med 2016;4:894-901.

10. Boucly A, Savale L, Weatherald J, Montani D, Jevnikar M, Jaïs X, et al. Impact of initial treatment strategy on long-term survival in pulmonary arterial hypertension (PAH) [abstract]. Eur Respir J 2018;52:OA271.

11. Boucly A, Savale L, Weatherald JC, Montani D, Cottin V, Dauphin C, et al. Impact of initial triple combination therapy on long-term survival in pulmonary arterial hypertension (PAH) [abstract]. Am J Respir Crit Care Med 2019;199:A5585.

12. Kylhammar D, Kjellström B, Hjalmarsson C, Jansson K, Nisell M, Söderberg $S$, et al. A comprehensive risk stratification at early follow-up determines prognosis in pulmonary arterial hypertension. Eur Heart $J$ 2018;39:4175-4181.

13. Hoeper MM, Kramer T, Pan Z, Eichstaedt CA, Spiesshoefer J, Benjamin $\mathrm{N}$, et al. Mortality in pulmonary arterial hypertension: prediction by the 2015 European pulmonary hypertension guidelines risk stratification model. Eur Respir J 2017;50:1700740.

14. Boucly A, Weatherald J, Savale L, Jaïs X, Cottin V, Prevot G, et al. Risk assessment, prognosis and guideline implementation in pulmonary arterial hypertension. Eur Respir J 2017;50:1700889.
15. Benza RL, Gomberg-Maitland M, Elliott CG, Farber HW, Foreman AJ, Frost $A E$, et al. Predicting survival in patients with pulmonary arterial hypertension: the REVEAL risk score calculator 2.0 and comparison with ESC/ERS-based risk assessment strategies. Chest 2019;156:323-337.

16. Nickel N, Golpon H, Greer M, Knudsen L, Olsson K, Westerkamp V, et al. The prognostic impact of follow-up assessments in patients with idiopathic pulmonary arterial hypertension. Eur Respir J 2012; 39:589-596.

17. Weatherald J, Boucly A, Launay D, Cottin V, Prévot G, Bourlier D, et al. Haemodynamics and serial risk assessment in systemic sclerosis associated pulmonary arterial hypertension. Eur Respir J 2018;52: 1800678.

18. Benza RL, Miller DP, Foreman AJ, Frost AE, Badesch DB, Benton WW, et al. Prognostic implications of serial risk score assessments in patients with pulmonary arterial hypertension: a Registry to Evaluate Early and Long-term Pulmonary Arterial Hypertension Disease Management (REVEAL) analysis. J Heart Lung Transplant 2015;34: 356-361.

19. Frost AE, Hoeper MM, Barberá JA, Vachiery J-L, Blair C, Langley J, et al. Risk-stratified outcomes with initial combination therapy in pulmonary arterial hypertension: application of the REVEAL risk score. J Heart Lung Transplant 2018;37:1410-1417.

20. Barst RJ, Rubin LJ, Long WA, McGoon MD, Rich S, Badesch DB, et al.; Primary Pulmonary Hypertension Study Group. A comparison of continuous intravenous epoprostenol (prostacyclin) with conventional therapy for primary pulmonary hypertension. N Engl J Med 1996;334: 296-301.

21. Sitbon O, Humbert M, Nunes $H$, Parent F, Garcia G, Hervé $P$, et al. Long-term intravenous epoprostenol infusion in primary pulmonary hypertension: prognostic factors and survival. J Am Coll Cardiol 2002; 40:780-788.

22. McLaughlin VV, Shillington A, Rich S. Survival in primary pulmonary hypertension: the impact of epoprostenol therapy. Circulation 2002; 106:1477-1482.

23. Humbert M, Sitbon $O$, Simonneau G. Treatment of pulmonary arterial hypertension. N Engl J Med 2004;351:1425-1436.

24. Humbert M, Lau EMT, Montani D, Jaïs X, Sitbon O, Simonneau G. Advances in therapeutic interventions for patients with pulmonary arterial hypertension. Circulation 2014;130:2189-2208.

25. Chin KM, Sitbon O, Doelberg M, Gibbs JSSR, Hoeper MM, Martin N, et al. Efficacy and safety of initial triple oral versus initial double oral combination therapy in patients with newly diagnosed pulmonary arterial hypertension (PAH): results of the randomized controlled TRITON study [abstract]. Am J Respir Crit Care Med 2020;201: A2928.

26. Galiè N, Hoeper MM, Humbert M, Torbicki A, Vachiery J-L, Barbera JA, et al.; Task Force for Diagnosis and Treatment of Pulmonary Hypertension of European Society of Cardiology (ESC); European Respiratory Society (ERS); International Society of Heart and Lung Transplantation (ISHLT). Guidelines for the diagnosis and treatment of pulmonary hypertension. Eur Respir J 2009;34:1219-1263.

27. Galiè N, Hoeper MM, Humbert M, Torbicki A, Vachiery J-L, Barbera JA, et al.; ESC Committee for Practice Guidelines (CPG). Guidelines for the diagnosis and treatment of pulmonary hypertension: the Task Force for the Diagnosis and Treatment of Pulmonary Hypertension of the European Society of Cardiology (ESC) and the European Respiratory Society (ERS), endorsed by the International Society of Heart and Lung Transplantation (ISHLT). Eur Heart J 2009;30:2493-2537.

28. Savale L, Guimas M, Ebstein N, Fertin M, Jevnikar M, Renard S, et al. Portopulmonary hypertension in the current era of pulmonary hypertension management. J Hepatol 2020;73:130-139. 